Slaviša Đukanović,

poručnik, dipl. inž. 224. Centar za EI i PED,

Batajnica

\section{IZVIĐANJE SATELITSKIH KOMUNIKACIJA U FUNKCIJI SAVREMENIH OPERACIJA}

UDC: 623.611 .629 .783$]: 355.42 / .43$

Rezime:

Raspoloživi vojni resursi u bilo kojoj kategoriji nisu kritični u mirnodopskom periodu, jer se dimenzionišu za ratno naprezanje određenog nivoa. Međutim, u uslovima izvođenja borbenih dejstava postoje ekstremi u zahtevima za angažovanjem, koje sistemi ne mogu da izdrže. Takav slučaj je kod satelitskih komunikacija. U radu su prezentovane taktičko-tehničke $i$ dinamičke osobine komercijalnih (INMARSAT, INTELSAT, IRIDIJUM...) $i$ vojnih (DSCS, FLEET-SATCOM, NATO, SKYNET ...) satelitskih sistema, koje su bitne za uspešno vođenje elektronskog rata. Takođe, dat je pregled raspoloživih korisničkih servisa savremenih satelitskih sistema (Internet provajding, video-konferencije, prenos multimedija uživo, fax, e-mail, voice). Nova generacija širokopojasnih satelita, koja se pušta u rad tokom ove godine, omogućiće globalni roming navedenih servisa INMARSAT satelitskom sistemu koji se sve češće koristi u vojne svrhe. U perspektivi je da se usluge koje pružaju satelitski sistemi (komunikacioni, navigacioni, izviđački, meteorološki ...) stave na raspolaganje nižim taktičkim jedinicama, vazduhoplovima, pa čak i svakom vojniku ponaosob. Poznavanje satelitskih sistema potencijalnog agresora pruža mogućnost da se odrede ranjive tačke samog sistema sa aspekta izviđanja $i$ ometanja.

Ključne reči: satelit, servisi, aplikacije, elektronsko izvidanje, operacije, sistemi, terminal, orbite.

\title{
RECONNAISSANCE OF SATELLITE COMMUNICATIONS IN CONTEMPORARY OPERATIONS
}

Summary:

Available military resources in any category are not critical in peace since they are tailored for military use under extreme conditions. However, some systems such as satellite communications, cannot meet extreme requirements during combat actions. The paper presents tactical and technical specifications and dynamic characteristics of commercial (INMARSAT., INTELSAT, IRIDIJUM,...) and military (DSCS, FLEET-SATCOM, NATO, SKYNET,...) satellite systems which are important for electronic warfare. The paper also gives available user services of contemporary satellite systems (Internet providing, videoconferences, live multi-media, fax, e-mail, voice). A new generation of broadband satellites, due to be operational this year, vill provide global rooming for these services to the INMARSAT satellite system which experiences a growing military use. Tendencies are that the services of satellite systems (communication, navigation, reconnaissance, meteorological ones,...) are to be put at disposal to lower tactical units, aircraft and even to each particular soldier. Knowing satellite systems of potential agressors enables the determination of satellite system weak points from the point of view of reconnaissance and jamming.

Key words: satellite, services, applications, electronic reconnaissance, operations, systems, terminal, orbits.

\section{Uvod}

Telekomunikacije su ključni element svake savremene vojske. Potreba za satelitskim segmentom postaje neobično značajna zbog malog broja kopnenih jedinica raspoređenih po svetu. Radi sprečavanja iznenađenja bilo koje vrste po- 
trebe za ovakvim vidom podrške su opravdane. Sateliti omogućavaju direktnu vezu sa jedinicama na bojnom polju.

Laki, pokretni terminali mogu se vrlo brzo na bilo kojoj lokaciji postaviti za svega nekoliko sati, što omogućava konstantan kontakt sa komandnim vrhom. Imati u posedu informaciju o rasporedu protivnika, snazi i sredstvima koje angažuje, i taktici koju primenjuje, predstavlja vrhunac sistema prikupljanja podataka. Presretanjem satelitskih komunikacija dolazi se do određenih informacija značajnih za procenu neprijatelja.

Detektovati, tj. presresti komunikaciju od interesa i obezbediti da izviđački sistem ostane na praćenju, primarni je zadatak sistema za elektronsko izviđanje. Kada se razmatra mogućnost izviđanja satelitskih komunikacija, treba imati u vidu bitnu specifičnost koja se ne javlja ni kod jednog drugog komunikacionog sistema koji može biti objekat elektronskog rata. To je relativna geometrija učesnika u elektronskoj igri, ne samo međusobna udaljenost, gde je izviđačka stanica po pravilu bliža korisničkom terminalu od satelita ili nadmorske visine učesnika.

\section{Komercijalni satelitski sistemi u vojnoj primeni}

\section{Mobilne satelitske komunikacije - MSK}

Mobilna satelitska služba predstavlja radiokomunikacioni servis između pokretnih zemaljskih satelitskih stanica (ZSS) i jedne ili više kosmičkih stanica, ili između kosmičkih stanica koje se mogu koristiti u ovoj službi. Pokretne ZSS mogu biti locirane na platformama na kopnu, bro- dovima i moru tj. na objektima, kao što su vozila, letelice, plovila, itd.

Pokretni sistem savremenih MSK-a, pre svega ima globalni karakter, u okviru kojeg postoje izvesni regionalni sistemi. S obzirom na svrsishodnost i specifičnost, MSK se uglavnom mogu podeliti na dva osnovna i međusobno zavisna integralna sistema: komercijalni i nekomercijalni. Međutim, njihov specifičan podsistem predstavljaju vojne MSK. Prvobitni komercijalni sistem uspostavljen je sa uvođenjem multinacionalnog MARISAT sistema, koji je kasnije prerastao u INMARSAT sistem. Satelitske komunikacije podrazumevaju veći broj bežičnih repetitorskih stanica (satelita) kojima se mikrovalnim komunikacijama omogućava komunikacija između geografski udaljenih područja. Satelitske veze mogu biti uspostavljene na različitim frekvencijskim područjima i koriste različite noseće frekvencije za prijem (zemaljska stanica - satelit) i predaju (satelit - zemaljska stanica).

Sateliti mogu biti postavljeni u orbitama sa različitim putanjama, visinom i oblikom putanje (kružna ili elipsasta). Prema orbitalnom radijusu (udaljenost satelita $\mathrm{i}$ zemljine površine), svi sateliti mogu se svrstati u tri kategorije (slika 1): LEO (Low-

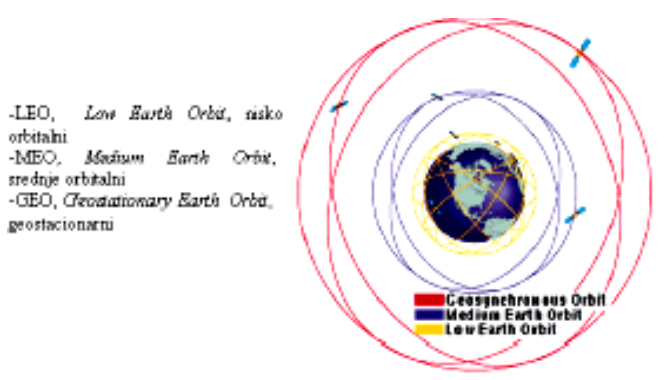

Sl. 1 - Satelitski sistemi 
Prednosti i mane satelitskih sistema s obzirom na položaj

\begin{tabular}{|c|c|c|c|}
\hline Tip & LEO & MEO & GEO \\
\hline Visina & $160-480 \mathrm{~km}$ & $9600-19000 \mathrm{~km}$ & $36000 \mathrm{~km}$ \\
\hline Vidokrug & $>15 \min$ & $2-4$ sata & 24 sata \\
\hline Prednosti & $\begin{array}{l}\text { 1. Niski troškovi lansiranja } \\
\text { 2. Kratko vreme kašnjenja signala } \\
\text { 3. Mali gubitak putanje, PSD } \\
\text { malih dimenzija i snage }\end{array}$ & $\begin{array}{l}\text { 1. Umereni troškovi } \\
\text { lansiranja } \\
\text { 2. Malo vreme } \\
\text { kašnjenja signala }\end{array}$ & $\begin{array}{l}\text { 1. Pokriva } 42,2 \% \text { Zemljine } \\
\text { površine } \\
\text { 2. Konstantan položaj u } \\
\text { odnosu na određenu tačku } \\
\text { na Zemlji } \\
\text { 3. Nema problema zbog } \\
\text { Doplerovog efekta }\end{array}$ \\
\hline Mane & 1. Kratak vek trajanja & $\begin{array}{l}\text { 1. Veće vreme } \\
\text { kašnjenja signala } \\
\text { 2. Veći gubitak putanje }\end{array}$ & $\begin{array}{l}\text { 1. Veliko vreme kašnjenja } \\
\text { signala } \\
\text { 2. Skupe zemaljske stanice }\end{array}$ \\
\hline
\end{tabular}

EarthOrbit), MEO (MediumEarthOrbit) i GEO (GeostationaryEarthOrbit).

\section{INMARSAT sistem MSK}

Početkom februara 1982. godine, INMARSAT organizacija zvanično je transformisana iz MARISAT sistema MSK. Organizacija je prvobitno započela funkcionisanje sa INMARSAT standard - A sistemom MSS i ZSS samo za pomorske aplikacije, nešto kasnije unapredila standard $-\mathrm{S}$ a danas omogućava upotrebu najnovijih standarda B, D, E i M (slika 2). Kosmički segment se sastoji iz konstelacije operacionih i rezervnih GSS sa transponderima i sistemom za TT\&S. Zemaljski segment obuhvata sve ZSS na kopnu, pomoćne stanice i službe,

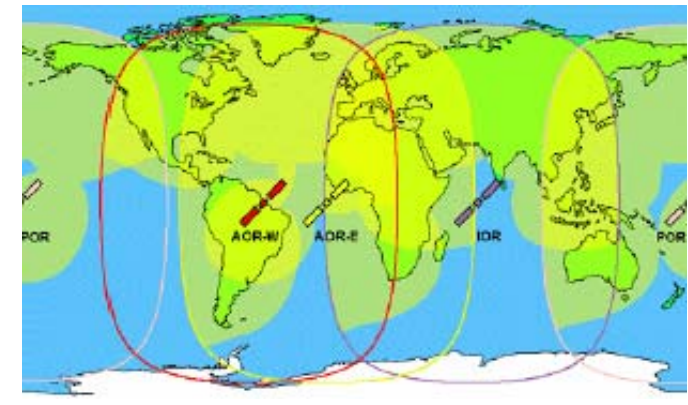

Sl. 2 - Granice opsluživanja INMARSAT sistema pokretne MSS ugrađene na plovnim objektima, letelicama, kao i na svim kopnenim saobraćajnim sredstvima.

Najnovija konfiguracija INMARSAT kosmičkog segmenta je sledeća:

1. AOR-W - Operacioni sateliti: INMARSAT-2 F4 (pozicija 54.0W)

- Rezervni satelit: INMARSAT-2 F2 (pozicija 55.0W)

2. AOR-E - Operacioni satelit: INMARSAT-3 F2 (pozicija 15.5W)

3. IOR - Operacioni satelit: INMARSAT-3 F1 (pozicija 64.0W)

- Rezervni satelit: INMARSAT-2 F3 (pozicija 65.0W)

4. IOR - Operacioni satelit: INMARSAT-3 F3 (pozicija 178.0W)

- Rezervni satelit: INMARSAT-2 F1 (pozicija 179.0W)

\section{INMARSAT sistem bezbednosnih komunikacija}

Globalni bezbedonosni komunikacioni sistem čini integraciju INMARSAT, COSPASSARSAT i GMDSS sistema. Ovaj sistem je predstavljen sa bezbedonosnim INMARSAT radionosačem Lopsega. Svi signali za opasnost, hitnost i sigurnost prenose se pomoću MSS IN- 
MARSAT-A i njegovih TEL i TLX terminala. Međutim, INMARSAT 'Priority 3' sistem može se isključivo upotrebiti prilikom slanja signala za opasnost sa TLX (SOS) ili TEL (MayDay) ili prilikom poziva kada je život čoveka u neposrednoj opasnosti.

\section{INMARSAT standardi za pomorske aplikacije}

INMARSAT je razradio nove digitalne standarde: B, C, M i mini-M za primenu na svim brodovima i ostalim plovnim i stacionarnim objektima na moru, kao što su platforme za istraživanje nafte, i uveo standard-E u pomorskim bezbedonosnim komunikacijama.

\section{INMARSAT GAN (M4) standard za prenošenje $i$ upotrebu na kopnu}

INMARSAT GAN predstavljen je 1999. godine kao proširena verzija mini-M standarda koja obuhvata sledeće servise: telefon (AMBE), HSD 56/64 kb/s, IPDS i fax/data niske brzine kao mini-M. GAN integriše po prvi put zajedničke IT globalne mreže sa mobilnim komunikacionim mrežama, koji sadrži dva rasprostranjena i fleksibilna servisa Mobile ISDN i skoro izbačen Mobile Packet Data Service (MPDS).

Tabela 2

INMARSAT standardi za pomorske aplikacije

\begin{tabular}{|c|c|c|c|c|}
\hline Standard & $\mathrm{B}$ & $\mathrm{C}$ & $\mathrm{M}$ & mini-M \\
\hline $\begin{array}{l}\text { Frekventni } \\
\text { opseg }(\mathrm{MHz})\end{array}$ & $\begin{array}{l}1525,0 \text { do } 1545,0 \mathrm{Rx} \\
1626,5 \text { do } 1646,5 \mathrm{Tx}\end{array}$ & $\begin{array}{l}1530,0 \text { do } 1545,0 \mathrm{Rx} \\
1626,5 \text { do } 1646,5 \mathrm{Tx}\end{array}$ & $\begin{array}{l}1530,0 \text { do } 1545,0 \mathrm{Rx} \\
1631,5 \text { do } 1646,5 \mathrm{Tx}\end{array}$ & $\begin{array}{l}1525,0 \text { do } 1559,0 \mathrm{Rx} \\
1626,5 \text { do } 1660,5 \mathrm{Tx}\end{array}$ \\
\hline Kanalski razmak & $20 \mathrm{KHz}$ & $5 \mathrm{KHz}$ & $10 \mathrm{KHz}$ & $1,25 \mathrm{KHz}$ \\
\hline EIRP & $\begin{array}{l}25 \text { do } 33 \mathrm{dBW} \text { za } \\
\text { nisku i visoku snagu }\end{array}$ & $\begin{array}{l}\text { minimum } 14 \mathrm{dBW} \\
\text { na } 5^{\circ} \text { elevacije }\end{array}$ & $\begin{array}{l}21 \text { do } 27 \mathrm{dBW} \text { za } \\
\text { nisku i visoku snagu }\end{array}$ & $\begin{array}{l}11 \text { do } 17 \mathrm{dBW} \text { sa } \\
\text { korakom } 2 \mathrm{~dB}\end{array}$ \\
\hline $\mathrm{G} / \mathrm{T}$ & $-4 \mathrm{~dB} / \mathrm{K}$ & $\begin{array}{l}-23 \mathrm{~dB} / \mathrm{K} \text { na } 5^{\circ} \\
\text { elevacije }\end{array}$ & $-10 \mathrm{~dB} / \mathrm{K}$ & $-17 \mathrm{~dB} / \mathrm{K}$ \\
\hline Potrošnja & $200 \mathrm{~W} R x$ i $300 \mathrm{~W}$ Tx & $15 \mathrm{~W}$ Rx i $50 \mathrm{~W}$ Tx & $30 \mathrm{~W}$ stb i $130 \mathrm{~W}$ Tx & $370 \mathrm{~mW}$ Rx $5 \mathrm{~W}$ Tx \\
\hline NPU & $\begin{array}{l}\text { Antena parabolična } 0,9, \\
\text { težina oko } 90 \mathrm{~kg} \text { sa } \\
\text { platformom i kupolom, } \\
\text { širina snopa } 15^{\circ} \text {. } \\
\text { Antensko pojačanje je } \\
21 \mathrm{~dB} \text {. }\end{array}$ & $\begin{array}{l}\text { Mala i konična antena } \\
\text { INMARSAT-C/GPS } \\
\text { Težina oko } 2 \mathrm{~kg} \text { sa } \\
\text { postoljem i kupolom. } \\
\text { Sirokopojasna } \\
\text { polarizacija desne } \\
\text { ruke. Antensko } \\
\text { pojačanje je oko } 6 \mathrm{~dB} \text {. }\end{array}$ & $\begin{array}{l}\text { Antena parabolična } \\
\text { diametra oko } 0,2 \mathrm{~m} \\
\text { (ima sistem za } \\
\text { stabilizaciju) sa } \\
\text { KPDR, težina oko } \\
4 \mathrm{~kg} \text { sa platformom i } \\
\text { kupolom. Širina } \\
\text { snopa } 15^{\circ} \text {. Antensko } \\
\text { pojačanje je oko } \\
14,5 \mathrm{~dB} \text {. }\end{array}$ & $\begin{array}{l}\text { Antena parabolična } \\
0,2 \mathrm{~m} \text { (ima sistem za } \\
\text { stabilizaciju) sa } \\
\text { KPDR, težina oko } \\
2 \text { kg sa platformom } \\
\text { i kupolom, širina } \\
\text { snopa } 15 \text { stepeni, } \\
\text { antensko pojačanje } \\
\text { je oko } 15 \text { dB. }\end{array}$ \\
\hline Modulacija & $\begin{array}{l}\text { O-QPSK za TEL, RAX } \\
\text { i prenos podataka, } \\
\text { BPSK (Rx) i O-QPSK } \\
\text { (Tx) za TLX }\end{array}$ & $\begin{array}{l}1200 \text { simbola/sec } \\
\text { BPSK, FEC } \\
\text { kodiranje brzinom } \\
\text { 1/2, pristup pomoću } \\
\text { SLOTTED ALOHA, } \\
\text { TDMA\&FDMA }\end{array}$ & $\begin{array}{l}5,6 \mathrm{~Kb} / \mathrm{s} \mathrm{O}-\mathrm{QPSK} \\
\mathrm{SCPC} \\
\text { (TEL/FAX/DATA), } \\
6 \mathrm{~Kb} / \mathrm{s}, \mathrm{BPSK} \text { TDM } \\
5,6 \mathrm{~Kb} / \mathrm{s} \text { O-QPSK } \\
\text { SCPC } \\
\text { (TEL/FAX/DATA), } \\
3 \mathrm{~Kb} / \mathrm{s} \mathrm{BPSK} \mathrm{TDM}\end{array}$ & $\begin{array}{l}5,6 \mathrm{~Kb} / \mathrm{s} \text { OQPSK } \\
\text { SCPC } \\
\text { (TEL/FAX/DATA), } \\
6 \mathrm{~Kb} / \mathrm{s} \mathrm{BPSK} \mathrm{TDM} \\
5,6 \mathrm{~Kb} / \mathrm{s} \text { O-QPSK } \\
\text { SCPC } \\
\text { (TEL/FAX/DATA) } \\
3 \mathrm{~Kb} / \mathrm{s} \mathrm{BPSK} \mathrm{TDM}\end{array}$ \\
\hline Servisi & $\begin{array}{l}\text { Telefon } 16 \mathrm{~kb} / \mathrm{s} \text { APC, } \\
\text { Fax } 14,4 \mathrm{~kb} / \mathrm{s}(9,6 \mathrm{~kb} / \mathrm{s}) \\
\text { Data } 9,6 \mathrm{~kb} / \mathrm{s} \\
\text { HSD } 64 \mathrm{~kb} / \mathrm{s}\end{array}$ & $\begin{array}{l}\text { dupleks kanali za } \\
\text { podatke i poruke } \\
\text { (sms i E-mail } \\
\text { maksimalno } 32000 \\
\text { karaktera) }\end{array}$ & $\begin{array}{l}\text { telefon IMBE } \\
\text { fax } 2,4 \mathrm{~kb} / \mathrm{s} \\
\text { data } 2,4 \mathrm{~kb} / \mathrm{s}\end{array}$ & $\begin{array}{l}\text { telefon AMBE } \\
\text { fax } 2,4 \mathrm{~kb} / \mathrm{s} \\
\text { data } 2,4 \mathrm{~kb} / \mathrm{s}\end{array}$ \\
\hline Klimatski uslovi & \multicolumn{4}{|c|}{ Temperatura od $-25^{\circ}$ do $+55^{\circ} \mathrm{C}$, Vlažnost vazduha oko $95 \%$, Brzina vetra do $100 \mathrm{Nm} / \mathrm{s}$} \\
\hline Brodski uslovi & \multicolumn{4}{|c|}{ Posrtanje i ljuljanje $10 / 30 \%$} \\
\hline
\end{tabular}




\section{INMARSAT standardi za vazduhoplovne aplikacije}

Aero sistem nudi TEL, FAX i DATA servise za potrebe putnika, aviooperatora, administracije i kontrole leta na aerodromima, avionima i ostalim vrstama letelica. Svi pozivi se upućuju sa aviona posredstvom ZSS i TTM do pretplatnika u celom svetu. INMARSAT je za period od deset godina razradio sledeće avio standarde: $\mathrm{C}, \mathrm{H}, \mathrm{I}, \mathrm{L}$ i mini-M, koji se mogu ugradivati na svim vrstama aviona i letelica.

\section{Standard mini-M ASS}

Aero mini-M je dizajniran na osno$\mathrm{vu}$ iskustva i prednosti koje su stečene praktičnim korišćenjem ovih standarda za pomorske i kopnene aplikacije. On se koristi za interavionske $\mathrm{i}$ druge vrste veza: dupleks jednokanalni TEL (PSTN) i ima mogućnost TEL šifrovanja, dupleks FAX i DATA posredstvom RS uz korišćenje SIM kartice, zatim koristi sektorsku prekrivenost Inmarsat-3 GSS, prenos X-25 i X-400 elektronske pošte. Ima mogućnost priključka na zemaljsku PSTN i ISDH sa ukupnom masom uređaja 4,5 kg koji podržava automatsko slanje podataka o poziciji i ne podržava ICAO zahteve u vezi bezbedonosnih komunikacija.

\section{INTELSAT}

INTELSAT (International Telecommunications Sattelite Consorcium) je

INMARSAT standardi za vazduhoplovne aplikacije

Tabela 3

\begin{tabular}{|c|c|c|c|c|}
\hline Standard & $\mathrm{C}$ & $\mathrm{H}$ & I & $\mathrm{L}$ \\
\hline $\begin{array}{l}\text { Frekventni } \\
\text { opseg }(\mathrm{MHz})\end{array}$ & $\begin{array}{l}1530,0 \text { do } 1545,0 \mathrm{Rx} \\
1626,5 \text { do } 1660,5 \mathrm{Tx}\end{array}$ & $\begin{array}{l}1530,0 \text { do } 1559,0 \mathrm{Rx} \\
1626,5 \text { do } 1660,5 \mathrm{Tx}\end{array}$ & $\begin{array}{l}1535,0 \text { do } 1560 \mathrm{Rx} \\
1626,5 \text { do } 1660,5 \mathrm{Tx}\end{array}$ & $\begin{array}{l}1525,0 \text { do } 1559,0 \mathrm{Rx} \\
1626,5 \text { do } 1660,5 \mathrm{Tx}\end{array}$ \\
\hline Kanalski razmak & $5 \mathrm{KHz}$ & $17,5 \mathrm{KHz}$ & $2,5 \mathrm{KHz}$ & $5 \mathrm{KHz}$ \\
\hline EIRP & $12 \mathrm{dBW}$ & Između 12 i $17 \mathrm{dBW}$ & $\begin{array}{l}16,5 \mathrm{kBW} \\
\text { maksimalno }\end{array}$ & $\begin{array}{l}\text { Nominalan } 19,5 \mathrm{kBW} \\
16,5 \mathrm{dBW} \text { min. }\end{array}$ \\
\hline $\mathrm{G} / \mathrm{T}$ & $\begin{array}{l}-32 \mathrm{~dB} / \mathrm{K} \text { na } 5^{\circ} \\
\text { elevacije }\end{array}$ & $\begin{array}{l}-13 \mathrm{~dB} / \mathrm{K} \text { na } 5^{\circ} \\
\text { elevacije }\end{array}$ & $\begin{array}{l}-19 \mathrm{~dB} / \mathrm{K} \text { na } 5^{\circ} \\
\text { elevacije }\end{array}$ & $\begin{array}{l}-13 \mathrm{~dB} / \mathrm{K} \text { na } 5^{\circ} \\
\text { elevacije }\end{array}$ \\
\hline Potrošnja & 9,5 W Rx i $80 \mathrm{~W}$ Tx & $15 \mathrm{~W} \mathrm{Rx}$ i $60 \mathrm{~W}$ Tx & $10 \mathrm{~W} \mathrm{Rx}$ i $50 \mathrm{~W}$ Tx & $10 \mathrm{~W}$ Rx i $50 \mathrm{~W}$ Tx \\
\hline NPU & $\begin{array}{l}\text { Antena je integralna } \\
\text { inmarsat-C GPS } \\
\text { širokopojasna bez } \\
\text { upravljanja sa KPDP } \\
\text { Masa } 2,3 \mathrm{~kg}\end{array}$ & $\begin{array}{l}\text { Antena je HighGain } \\
\text { sa BSU za } \\
\text { usmeravanje i } \\
\text { KPDR. Odnos osa } \\
>6 \text { dB unutar } \\
\text { antenske } \\
\text { pokrivenosti i za sve } \\
\text { uglove njenog } \\
\text { usmeravanja }\end{array}$ & $\begin{array}{l}\text { Antena je } \\
\text { Intermediate-gain sa } \\
\text { BSU za usmeravanje } \\
\text { i KPDR. Pokrivenost } \\
\text { >95\% za sve uglove } \\
\text { njenog usmeravanja. } \\
\text { Bočna lepeza prelazi } \\
8,5 \text { dB unutar zone } \\
\text { pokrivanja }\end{array}$ & $\begin{array}{l}\text { Antena je Intermedi- } \\
\text { ate-gain sa BSU za } \\
\text { usmeravanje i } \\
\text { KPDR. Pokrivenost } \\
\text { >95\% za sve uglove } \\
\text { njenog usmeravanja. } \\
\text { Bočna lepeza prelazi } \\
8,5 \text { dB unutar zone } \\
\text { pokrivanja }\end{array}$ \\
\hline Modulacija & $\begin{array}{l}1200 \text { simbola/sek } \\
\text { BPSK, FEC kodiranje } \\
\text { brzinom } 1 / 2, \mathrm{Rx} \\
\text { dužina rama } 8,64 \mathrm{~s}\end{array}$ & $\begin{array}{l}\text { QPSK sa pomakom } \\
\text { (avio primena)/BPSK, } \\
\text { APC sa MLQ } \\
\text { kodiranje, Rx dužina } \\
\text { rama } 500 \mathrm{~s}\end{array}$ & $\begin{array}{l}-8,4 \mathrm{k} / \mathrm{s} \text { A-QPSK C } \\
\text { kanala. } \\
\text { (TEL/FAX/DATA) - } \\
0,6 / 1,2 \mathrm{~Kb} / \mathrm{s} \text { A-BPSK } \\
\mathrm{Pi} \text { T kanali }\end{array}$ & $\begin{array}{l}\text { BPSK avio Rx. } \\
\text { Brzina prenosa } 600 \\
\text { b/s, Rx dužina rama } \\
2 \text { s, Tx DATA } \\
\text { brzina } 600 / 1200 \mathrm{~b} / \mathrm{s} \text {. }\end{array}$ \\
\hline Priključci & $\begin{array}{l}\text { TEL, FAX na } 2 \text { žice } \\
\text { PC, DTE, SIM kao za } \\
\text { GSM, napajanje }\end{array}$ & $\begin{array}{l}\text { TEL i FAX Group- } \\
\text { III PC, DTE, } \\
\text { napajanje }\end{array}$ & $\begin{array}{l}\text { TEL, FAX i } \\
\text { MODEM, PC, DTE, } \\
\text { napajanje }\end{array}$ & $\begin{array}{l}\text { PC i DTE } \\
\text { Napajanje }\end{array}$ \\
\hline Klimatski uslovi & \multicolumn{4}{|c|}{$\begin{array}{c}\text { Temperatura od }-20 \text { do }+55^{\circ} \mathrm{C}(\mathrm{Rx} / \mathrm{Tx})-55 \text { do }+70^{\circ} \mathrm{C} \text { (Antena) Vlažnost vazduha oko } 95 \% \\
\text { Brzina vetra do } 100 \mathrm{Nm} / \mathrm{s} \text { (antena) }\end{array}$} \\
\hline Avionski uslovi & \multicolumn{4}{|c|}{ Brzina oko $1000 \mathrm{~km} / \mathrm{h}$, ubrzanje minimalno $+/-1 \mathrm{~g}$} \\
\hline
\end{tabular}


međunarodni konzorcijum za telekomunikacione satelite sa sedištem u Vašingtonu, a osnovan je 1964. godine. Naša zemlja pristupila je INTELSAT-u 1970. godine. INTELSAT ima globalni sistem pokrivanja Zemlje pomoću satelita postavljenih u ekvatorijalnoj ravni iznad Atlantskog, Indijskog i Tihog okeana. Geografski položaj naše zemlje omogućava korišćenje atlantskog i indijskog satelita. Ovaj sistem se sastoji od dva elementa: vasionskog u vlasništvu INTELSAT-a, i zemaljskog koji čine satelitske stanice u vlasništvu Uprava zemalja na čijoj teritoriji se nalaze.

INTELSAT je kao prvi međunarodni satelitski konzorcijum još uvek najveći u svetu. Opslužuje oko 200 zemalja i za mnoge zemlje u razvoju omogućava jedinu vezu sa ostatkom sveta. Raspolaže vrlo širokim opsegom usluga kao što su:

- tačka-tačka javne komutacione usluge govor/podaci,

- video usluge, uključujući povremeno korišćenje i iznajmljivanje na duži period,

- specijalne poslovne usluge koje zadovoljavaju potrebe združenih korisnika,

- iznajmljene transpondere koji mogu biti prilagođeni mnogim namenama,

- domaće usluge koje dopunjuju telekomunikacionu infrastrukturu države,

- obnavljanje veze u slučaju prekida transokeanskih optičkih kablova.

INTELSAT-ov kosmički segment obuhvata 27 geostacionarnih satelita koji opslužuju četiri regiona. INTELSAT-ovi sateliti obezbeđuju četiri kategorije usluga: međunarodnu javnu komutiranu telefoniju, difuziju, privatne - profesionalne mreže, lokalne - regionalne komunikacije. Trenutno su u orbiti letelice iz serija V, V-A, V-A (IBC), VI, VII, VII-A i VIII. Neke od karakteristika ovih satelita date su u tabeli 5 .

Veze se ostvaruju na sledećim frekvencijama:

- veza na gore (Zemlja - satelit) 5,925-6,425 GHz

- veza na dole (satelit - Zemlja)

$3,700-4,200 \mathrm{GHz}$

\section{TELEDESIC}

Jedan od najambicioznijih mobilnih satelitskih sistema je sistem TELEDESIC. Planirano je obezbeđivanje širokopojasnog prenosa podataka do fiksnih i mobilnih terminala, globalno prekrivanje, mala verovatnoća greške po bitu $\left(\mathrm{BER}<10^{-10}\right)$. Planira se da sistem bude $\mathrm{u}$ mogućnosti da opsluži servise sa protocima podataka do $64 \mathrm{Mb} / \mathrm{s}$ (downlink) i do

Tabela 4

Pregled INTELSAT satelita

\begin{tabular}{|c|c|c|c|c|c|}
\hline & INTELSAT V & INTELSAT VI & INTELSAT VII & INTELSAT VIII & INTELSAT IX \\
\hline Glavni ugovarač & $\begin{array}{c}\text { Ford Aero } \\
\text { Space }\end{array}$ & $\begin{array}{c}\text { Hughes Aircraft } \\
\text { Company }\end{array}$ & $\begin{array}{c}\text { Space Systems } \\
\text { Loral }\end{array}$ & $\begin{array}{c}\text { Locheed } \\
\text { Martin }\end{array}$ & $\begin{array}{c}\text { Space Systems } \\
\text { Loral }\end{array}$ \\
\hline Prvi put u radu & 1980. & 1989. & 1993. & 1997. & Kraj 2000. \\
\hline $\begin{array}{c}\text { Masa na } \\
\text { lansiranju (kg) }\end{array}$ & 1950 & 4200 & 3800 & 3400 & 4400 \\
\hline Snaga satelita (W) & 1300 & 2000 & 4000 & 5400 & 8000 \\
\hline $\begin{array}{c}\text { Snaga signala u } \\
\text { zoni pokrivanja } \\
\text { (dBW) }\end{array}$ & 29 & 31 & 33 & 36 & 37 \\
\hline
\end{tabular}


Karakteristike serije INTELSAT-ovih satelita

\begin{tabular}{|c|c|c|c|c|c|c|c|}
\hline & $\mathrm{V}$ & $\mathrm{V}-\mathrm{A}$ & $\begin{array}{c}\text { V-A } \\
(\mathrm{IBC})\end{array}$ & $\mathrm{VI}$ & $\mathrm{VII}$ & VII-A & VIII \\
\hline Broj tel. kanala & 12000 & 15000 & 15000 & 24000 & 18000 & 22500 & 22500 \\
\hline $\begin{array}{c}\text { Ukupna širina } \\
\text { opsega (MHz) }\end{array}$ & 2137 & 2250 & 2270 & 3330 & 2432 & 2880 & 2856 \\
\hline Broj transpondera & 27 & 30 & 30 & 48 & 36 & 40 & 44 \\
\hline $\begin{array}{c}\text { Globalno pokrivanje, } \\
\text { EIRP (dBW) }\end{array}$ & 23,5 & 23,5 & 23,5 & 26,5 & $26 / 29$ & 29 & 29 \\
\hline $\begin{array}{c}\text { Snaga TWT } \\
\text { pojačavača (W) }\end{array}$ & 8,5 & 8,5 & 8,5 & 13,5 & $16 / 30$ & 30 & 10 \\
\hline Zapad EIRP (dBW) & 44,4 & 44,4 & $39,0-41,1$ & $44,7-47,7$ & $45,4-46,9$ & 47,9 & $44-47$ \\
\hline Istok EIRP (dBW) & 41,1 & 41,1 & $38,5-41,1$ & $44,7-47,7$ & $45,4-46,7$ & 47 & $44-47$ \\
\hline
\end{tabular}

$2 \mathrm{Mb} / \mathrm{s}$ (uplink). Sistem sadrži 288 aktivnih satelita i 36 rezervnih u 12 orbitalnih ravni (24 satelita po orbitalnoj ravni). Koristi se Ka-opseg: 28,6-29,1 GHz za uplink, 18,8-19,3 GHz za downlink.

Međusatelitske veze su laserske. Sistem je tako dizajniran da u svakom trenutku mobilni terminal ,vidi“" barem dva satelita (satelitski diverziti). Zemljina površina je podeljena na fiksnu mrežu od oko 20000 superćelija od kojih se svaka sastoji od 9 ćelija. Superćelija je kvadrat sa veličinom strana od $160 \mathrm{~km}$. Zona pokrivanja satelita obuhvata 64 superćelije, što znači jedna superćelija po snopu (otisak satelita se sastoji od 64 antenska snopa). Svaki snop ciklično skenira svaku od 9 ćelija unutar superćelije. TELEDESIC predlaže širok spektar servisa sa protocima od $16 \mathrm{~kb} / \mathrm{s}$ do $2,048 \mathrm{Mb} / \mathrm{s}$ za mobilne pretplatničke terminale, dok za fiksne terminale moguć je protok sa brzinama od $0,155-1,2 \mathrm{~Gb} / \mathrm{s}$. Pristupi kanalu su TDMA/SDMA/FDMA i moguće je ostvariti 100000 kanala po satelitu (protok od $16 \mathrm{~kb} / \mathrm{s}$ ).

\section{Iridijum}

Koncept globalnog satelitskog komunikacionog sistema Iridijum razvijen je od strane kompanije Motorola krajem 80-tih godina prošlog veka. Sistem Iridijum predstavlja lični komunikacioni sistem (PCS - Personal Communications System) baziran na satelitima koji se kreću u niskoj orbiti. Projektovan je sa ciljem da ostvari visoko kvalitetnu govornu komunikaciju širom sveta.

Pored toga, sistem omogućava prenos poruka i podataka malim brzinama. U vreme nastajanja, svojim načinom rada i globalnim pokrivanjem predstavljao je prvi sistem te vrste. Uprkos globalnom pokrivanju, glavni cilj njegovog razvoja bio je da pruži komunikacione servise u oblastima koje ne pokriva ni jedan drugi operater. Sačinjava ga 66 satelita koji se kreću po skoro polarnim orbitama u 6 ravni (11 satelita po ravni) kao i odgovarajući broj rezervnih satelita čija je uloga da preuzmu komunikaciju u slučaju otkaza nekog od 66 osnovnih satelita. U počeku sistem je projektovan da koristi 77 
satelita. Korisnik je uz pomoć sistema u mogućnosti da u svakom momentu odredi svoj položaj, što ima za posledicu da je korisnika uvek moguće locirati.

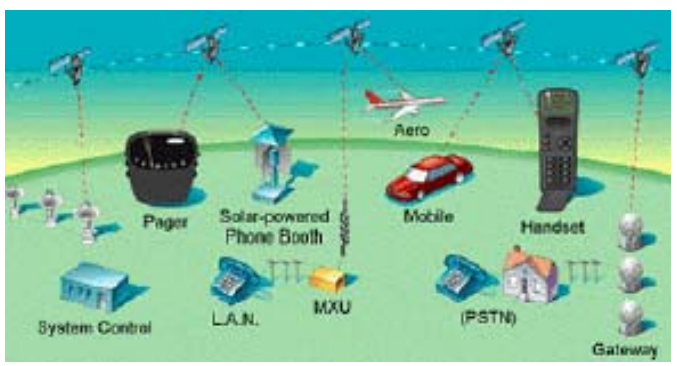

Sl. 3 - IRIDIJUM satelitski sistem

Veze između pojedinih satelita rade u Ka-opsegu radio spektra na frekvencijama 23,18-23,38 GHz. Ove međusatelitske veze ostvaruju se na način sličan packet switching systems. Signali između satelita i zemaljskih stanica takođe se razmenjuju u Ka-opsegu radio spektra. Za komunikaciju zemlja-satelit (uplink) koriste se frekvencije u opsegu 29,1-29,3 $\mathrm{GHz}$ a komunikacija satelit-zemlja (downlink) se odvija na 19,4-19,6 GHz. Ove veze omogućavaju da se poziv koji je upućen sa nekog mobilnog terminala prosledi do bilo kog drugog mobilnog terminala, ili do javne telefonske mreže. Važno je napomenuti da se Iridijum PCD ponaša kao dual-mod telefon koji vezu može da uspostavi bilo putem pomenute satelitske mreže, bilo putem postojeće infrastrukture mobilne telefonije na zemlji. U slučaju da korisnik nije u dometu zemaljskih baznih stanica veza se uspostavlja satelitskim sistemom. Korisnik, takođe, može podesiti svoj uređaj da uvek koristi usluge satelitske mreže (u slučaju da želi veću sigurnost ili želi da izbegne zemaljske tarife (kada se poziv tarifira po tarifama lokalnih mreža). Iridijum sistem je u stanju da pored govora prenosi poruke, digitalne podatke i faksimil brzinama od 2,4 kilobita u sekundi.

\section{Vojni satelitski sistemi \\ $D S C S$}

Satelitski sistem DSCS je odbrambeni satelitski komunikacioni sistem OS SAD (DSCS - Defence Satelite Communication System) koga čini 9 geostacionarnih satelita iznad: zapadnog Atlantika, 52,6W WLANT, istočnog Atlantika, 12W ELANT i Indijskog okeana, 60E-IO.

U vojnim satelitskim komunikacionim sistemima koriste se različiti tipovi modulacija. Izbor modulacije može delimično zavisiti od izbora šeme višestrukog pristupa ili od načina formiranja signala u proširenom spektru. Položaji navedenih satelita i oblasti koje oni pokrivaju prikazani su na slici 4 .

Zemaljski segment DSCS satelitskog sistema sadrži satelitske terminale koji su dodeljeni kopnenoj vojsci, mornarici, vazduhoplovnim snagama i mornaričko-pešadijskim jedinicama. Terminali koji se koriste u ovom satelitskom sistemu su standardizovani, mogu se postaviti na avione, brodove, fiksne stanice $i$ koriste se $u$ diplomatskim telekomunikacionim sistemima (DTC). Reč je o višekanalnim TACSAT terminalnim uređajima oznake AN/TSC-85/93 koji se koriste u jedinicama KoV i MDP, odnosno, AN/TSC94A/100A kod vazduhoplovnih snaga, pri čemu su kompatibilni sa uređajima sistema TRI-TAC i MSE. Terminalni uređaj AN/TCS-93 (pojedinačni uređaj) omogućava prenos jednog SVF nosioca za 


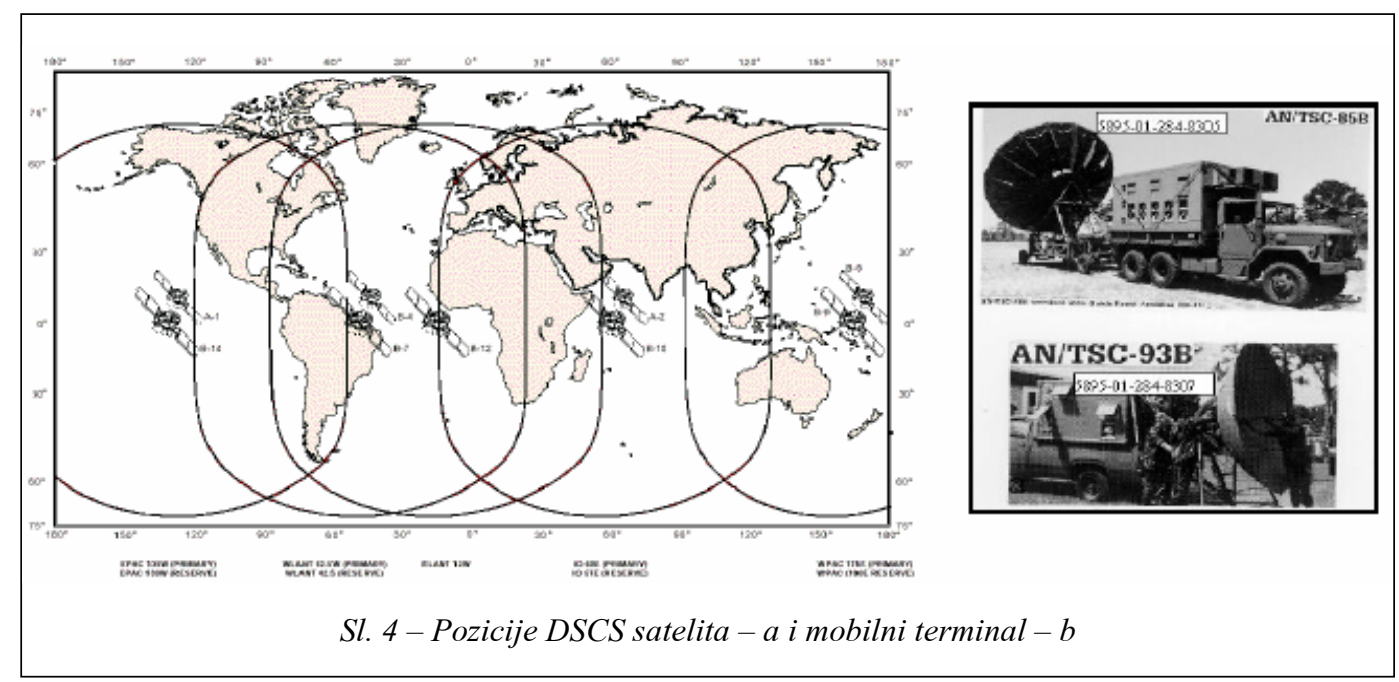

„Uplink“ vezu sa 24 telefonska kanala i/ili digitalnim podacima koje on multipleksira. Taktički terminal AN/TSC/93B i AN/TSC-85B i SHF opsega koristio se $u$ ratu u Zalivu (slika 4-b).

\section{SKYNET}

Satelitski sistem SKYNET koji pripada OS Velike Britanije takođe je interesantan sa aspekta EI. Koriste ga za održavanje taktičkih komunikacija sa svojom ratnom flotom. Sistem je projektovan 1966. godine dok je 1969. godine satelit SKYNET-1 postavljen iznad Indijskog okeana obezbeđujući 40 TLG kanala. Radi u opsegu 7/8 GHz i koristi 4 kanala sa širinama u opsegu od 60 do 135 MHz. Ratni brodovi opremljeni su MSS tipa 'Skott', koje održavaju vezu sa glavnim komandnim centrom $u$ pokrajini Hampshire a odatle se sva saopštenja prenose u Centar za obradu i raspodelu podataka u Londonu. Nova modifikacija MSS 'Skott', omogućuje TEL, TLG, i FAX veze, i prenos podataka u digitalnoj formi posredstvom DSCS-2 i 3 i NATO-4 sistema (LINK-11 i LINK-10).

\section{NATO IV}

NATO IV satelitski sistem obezbeđuje komunikaciju u UHF i SHF opsegu. Koriste se četiri kanala za SHF opseg. Namenjen je za obezbeđivanje šifrovanih TEL i TLG veza između komandnih štabova zemalja NATO i njihovih štabova, četa i ratnih brodova. Ovaj satelitski sistem pokriva sledeće zone: istočnu Kanadu, Atlantik, deo zapadne Afrike, Evropu i jugo-istočni deo Grenlanda (aproksimativno od $80^{\circ} \mathrm{W}$ do $60^{\circ} \mathrm{E}$ i od $25^{\circ} \mathrm{S}$ do $75^{\circ} \mathrm{N}$ ).

U tabeli 6 prikazani su neki od osnovnih parametara ovog sistema. Ovi parametri su identični sa parametrima sistema SKYNET 4 i DSCS tako da postoji mogućnost uzajamnog delovanja i podrške, radi optimalnog iskorišćenja svih vidova komunikacije za potrebe OS NATO. Prema dostupnim podacima u tabeli 6 dat je kratak pregled satelitskih sistema od interesa za elektronsko izviđanje, koji rade u SHF opsegu. 
Pregled satelitskih sistema koji rade u SHF opsegu

\begin{tabular}{|c|c|c|c|c|}
\hline Red. br. & Pripadnost & Frekvencijski opseg & $\begin{array}{c}\text { Broj satelita i njihova } \\
\text { pozicija }\end{array}$ & Napomena \\
\hline 1 & 2 & 3 & 4 & 5 \\
\hline 1. & $\begin{array}{l}\text { Odbrambeni satelitski } \\
\text { komunikacioni sistem OS SAD }\end{array}$ & $\begin{array}{l}\text { SHF up-link } 7,900- \\
8,400 \mathrm{GHz} \text { donji-link } \\
7,250-7,750 \mathrm{GHz}\end{array}$ & $\begin{array}{c}\text { Kosmički segment } \\
\text { DSCS III sadrži } 6 \\
\text { satelita }\end{array}$ & $\begin{array}{c}\text { Koristi 6-kanalne } \\
\text { transpondere sa FDM } \\
\text { raspodelom kanala. }\end{array}$ \\
\hline 2. & $\begin{array}{c}\text { Satelitski sistem OS Velike } \\
\text { Britanije SKYNET (SKYNET-4) }\end{array}$ & SHF $7 / 8 \mathrm{GHz}$ & $\begin{array}{c}4 \text { redundantna kanala } \\
\text { koji pokrivaju } \\
\text { Evropu i severni } \\
\text { Atlantik. }\end{array}$ & $\begin{array}{l}\text { SKYNET: 4A- } \\
34,0^{\circ} \mathrm{W}, 4 \mathrm{C}-0,9^{\circ} \mathrm{W} \\
4 \mathrm{D}-39,1^{\circ} \mathrm{E}, 4 \mathrm{E}- \\
53,1^{\circ} \mathrm{E}, 4 \mathrm{~F}-5,8^{\circ} \mathrm{E} .\end{array}$ \\
\hline 3. & NATO satelitski sistemi, NATO-III & $\mathrm{X}$ & $\begin{array}{c}\text { Tri kanala širine } 14 \\
\mathrm{MHz}, 85 \mathrm{MHz} \text { i } 550 \\
\mathrm{MHz}\end{array}$ & $\begin{array}{l}\text { Trebalo bi i da su } \\
\text { lansirani sateliti iz } \\
\text { faze NATO-IVB } \\
\left(20,2^{\circ} \mathrm{W}\right) \text {. NATO- } \\
\text { IVA }\left(17,8^{\circ} \mathrm{W}\right)\end{array}$ \\
\hline
\end{tabular}

\section{Zaključak}

Kao i kod svih drugih tipova komunikacija koje se koriste za vojne potrebe i kod satelitskih komunikacija vredi pravilo da su najzaštićenije one koje su namenjene najvišim komandnim nivoima ili najznačajnijim korisnicima. Zanemari li se ozbiljnost probijanja informacione zaštite, ostaje problem probijanja komunikacione zaštite. Ako ova zaštita podrazumeva prenos u proširenom spektru, tada pokušaj elektronskog izviđanja ima malo izgleda za uspeh. Elektronsko izviđanje komunikacija sa proširenim spektrom koje koriste mobilni učesnici na kopnu, u vazdušnom prostoru i na moru svakako ima smisla, jer može pružiti podatke o lokaciji, pokretu, aktivnosti i pripadnosti mreži izviđanog objekta. Dizajn nekih satelitskih komunikacionih sistema osta- vlja izvesne mogućnosti za EI i sa, na prvi pogled, nepovoljne lokacije. Satelitski komunikacioni sistemi koji ne koriste uopšte ili bar ne isključivo intersatelitske veze, već gateway ulaze na zemaljske komunikacione sisteme NCS posredno su ranjivi na EI uplink-a.

Bez poznavanja satelitskih komunikacija nemoguće je rekonstruisati sistem veza potencijalnog agresora i odrediti osetljive tačke sa aspekta EI. Osnovu sistema C3I savremenih armija čine upravo satelitske komunikacije. Značajni vojni efektivi u svetu danas teško mogu biti efikasno upotrebljeni i pokrenuti bez oslonca na satelitske komunikacione sisteme.

\section{Literatura:}

[1] Dukić, M.: Principi savremenih telekomunikacionih sistema, ETF Skripta. Beograd 2004.

[2] Stojčevski, Z.: Savremeni KIS i razvoj roda EI i PED, Stručni rad, VA, ŠNO, Beograd 2002. 